\title{
An immunochemical study of serological cross-reaction between lipopolysaccharides from Vibrio cholerae 022 and 0139
}

\author{
Yasunori Isshiki, ${ }^{1}+$ Seiichi Kondo, ${ }^{1}$ Takehiro Iguchi, ${ }^{1}$ Yasuhiro Sano, ${ }^{1}$ \\ Toshio Shimada ${ }^{2}$ and Kazuhito Hisatsune ${ }^{1}$
}

Author for correspondence: Kazuhito Hisatsune. Tel: +81 49271 7673. Fax: +81492717984.

1 Department of Microbiology, School of Pharmaceutical Sciences, Josai University, Sakado, Saitama 350-02, Japan

2 National Institute of Health, Toyama, Shinjukuku, Tokyo, Japan
A comparative chemical and serological study of the LPS of Vibrio cholerae 0139 and 022 was performed. Chemical analysis revealed that the sugar composition of the LPS of strain 022 was quite similar to that of 0139 LPS. Each contained D-glucose, L-glycero-D-manno-heptose, colitose (3,6-dideoxy-Lgalactose), D-fructose, D-glucosamine, D-quinovosamine and D-galacturonic acid. The 0 -antigenic relationship between the two strains was analysed by passive haemolysis (PH) and passive haemolysis inhibition (PHI) tests with the respective LPS being used as antigens to sensitize sheep red blood cells (SRBC) and, in the latter case, as inhibitors in a PH system that consisted of LPSsensitized SRBC, guinea-pig complement and anti-0139 or anti-022 antiserum, both unabsorbed and absorbed with the heterologous antigen. In the PH experiment, unabsorbed anti-0139 antiserum had haemolytic titres of 66000 and 22000 against 0139 LPS- and 022 LPS-sensitized SRBC, respectively; unabsorbed anti-022 antiserum had haemolytic titres of 900 and 13000, respectively. Thus, the anti-0139 antiserum contained an antibody that reacted with a heterologous 022 antigen at a high titre $(22000)$ and this antibody was completely removed from anti-0139 antiserum with the 022 antigen. The anti022 antiserum contained an antibody that reacted with the heterologous 0139 antigen at a low titre (900) and this antibody was completely removed from anti-022 antiserum with the 0139 antigen. In PHI tests 0139 LPS and 022 LPS each strongly inhibited (the $I_{50}$ of LPS ranged from 0.03 to $0.14 \mu \mathrm{g} \mathrm{ml}^{-1}$ ) the heterologous haemolytic systems of both 0139 LPS-sensitized SRBC/anti-022 antiserum and 022 LPS-sensitized SRBC/anti-0139 antiserm, which are substantially equivalent to the common antigen factor in the 0139 LPSsensitized SRBClanti-022 antiserum system and the common antigen factor in the 022 LPS-sensitized SRBC/anti-0139 antiserum system, respectively. The results indicated that the $\mathrm{O}$ antigen of 0139 is closely related to that of 022 in an $a, b-a, c$ type of relationship where $a$ is common antigenic factor, $b$ is an 0139-specific antigenic factor and $c$ is an 022-specific antigenic factor.

Keywords: lipopolysaccharide, Vibrio cbolerae O22, Vibrio cholerae $\mathrm{O} 139$

\section{INTRODUCTION}

The members of the species Vibrio cholerae are presently divided into two groups, namely $\mathrm{O} 1 \mathrm{~V}$. cholerae (cholera

†Present address: Department of Bacteriology, Kitasato Institute, Minato-ku, Tokyo 108, Japan

Abbreviations: DPS, degraded polysaccharide; Kdo, 2-keto-3deoxyoctonate; LOS, lipo-oligosaccharide; $\mathrm{PH}$, passive haemolysis; $\mathrm{PHI}$, passive haemolysis inhibition; SRBC, sheep red blood cells. vibrio) and non-O1 $V$.cholerae (NAG vibrio), on the basis of their respective $O$ antigens (heat-stable somatic antigens). The first group is further subdivided into Ogawa and Inaba $\mathrm{O}$ forms, while the latter is divided into 144 or more O forms (Shimada et al., 1994a). Historically, O1 $V$. cholerae has been regarded as the causative agent of the acute intestinal disease, cholera. However, the epidemic strain responsible for the recent fast-spreading cholera on the Indian subcontinent, which started in October 1992, was classified by Shimada et al. (1993) as V. cholerae O139 
synonym Bengal. The $\mathrm{O}$ antigen of Gram-negative bacteria, including $V$. cholerae, resides in the LPS that is located in the outer membranes of cell walls. LPS is a heteropolysaccharide composed of three moieties: lipid $A$, which is the centre of its endotoxic activity; a core polysaccharide; and an $\mathrm{O}$ polysaccharide chain that determines the serological O-antigenic specificity of the parent cells from which the LPS is derived (Lüderitz et al., 1971; Wilkinson, 1977). The chemical properties, in particular the sugar composition and molecular architecture, of LPS isolated from $V$. cholerae O139 were first reported by Hisatsune et al. (1993). It is of particular interest that the LPS contains colitose, which had not hitherto been found in $V$. cholerae or even in Vibrionaceae.

Recently, serological cross-reaction between $V$. cholerae O139 and O22 in agglutination and agglutinin absorption tests was reported (Shimada et al., 1994b). In this study, a comparative chemical and serological analysis was performed with LPS isolated from $V$. cholerae $\mathrm{O} 139$ and $\mathrm{O} 22$. The results demonstrated that the major $\mathrm{O}$ antigen of the O139 strain is a common antigen shared by the two strains, while the major $\mathrm{O}$ antigen of the $\mathrm{O} 22$ strain is an O22-specific antigen.

\section{METHODS}

Bacterial strains and growth conditions. $V$. cholerae $\mathrm{O} 22$ (169-68, reference strain) and O139 (MO 45, reference strain) strains were used in this study. The microbes were cultured in nutrient broth $(\mathrm{pH} 7 \cdot 4)$ at $37^{\circ} \mathrm{C}$ for $16 \mathrm{~h}$ with aeration. Cells were harvested by centrifugation after they had been killed by heating at $120^{\circ} \mathrm{C}$ for $20 \mathrm{~min}$. They were then washed with water and acetone-dried. $V$. cholerae O1 NIH 41 (Ogawa) and 569B (Inaba) were provided by Dr N. Ohtomo, The Chemo-Sero Therapeutic Institute, Kumamoto, Japan, and Salmonella typhimurium LT2 was provided by Dr M. Yoshida, Department of Bacteriology, Iwate Medical School, Morioka, Japan. These strains were also cultured in nutrient broth and the cells were acetone-dried after being killed by heating as described above.

Preparation and chemical modification of LPS. LPS was extracted from the acetone-dried cells by the hot phenol/water method (Westphal et al., 1952) and purified as described previously (Hisatsune et al., 1993). LPS was hydrolysed by treatment with $5 \%(\mathrm{v} / \mathrm{v})$ acetic acid at $100{ }^{\circ} \mathrm{C}$ for $2.5 \mathrm{~h}$ to yield a degraded polysaccharide (DPS) fraction that contained the polysaccharide portion of LPS. The DPS fraction was subjected to gel chromatography on a column $(3.6 \mathrm{~cm}$ i.d. $\times 100 \mathrm{~cm})$ of Sephadex G-50 (Pharmacia) which was eluted with distilled water and the effluent was monitored with a refractive index monitor (RID-6A, Shimadzu). The fractions corresponding to the polysaccharide portion of LPS were combined and lyophilysed. Dephosphorylation and oxidation of LPS were carried out as described previously (Kondo et al., 1991b) in $48 \%(\mathrm{v} / \mathrm{v})$ $\mathrm{HF}$ at $4{ }^{\circ} \mathrm{C}$ for $48 \mathrm{~h}$ and in $0.025 \mathrm{M} \mathrm{NaIO}_{4}$ at $0{ }^{\circ} \mathrm{C}$ for $120 \mathrm{~h}$, respectively. Methylation analysis was performed by the method of Hakomori (1964) and the methylated material was purified on a Sep-Pak C18 cartridge (Waters).

Analytical methods. Neutral sugars with the exception of fructose and colitose were analysed by GC as alditol acetates after hydrolysis in $2 \mathrm{M}$ trifluoroacetic acid at $120^{\circ} \mathrm{C}$ for $1 \mathrm{~h}$. Fructose and colitose were quantified by the previously reported method (Hisatsune et al., 1993). Amino sugars were analysed by $\mathrm{GC}$ as $N$-acetylaminoalditol acetates after hydrolysis in $4 \mathrm{M} \mathrm{HCl}$ at $100{ }^{\circ} \mathrm{C}$ for 16 h. 2-Keto-3-deoxyoctonate (Kdo) was estimated by Weissbach's periodate/thiobarbituric acid test (Weissbach \& Hurwitz, 1959) and Kdo phosphate was detected by GC and GC/MS using the method of Kondo et al. (1991b). Galacturonic acid was identified by GC and GC/MS as galactose $\left(6-2^{2} \mathrm{H}\right)$ that was prepared by methanolysis $\left(1 \mathrm{M} \mathrm{HCl}\right.$ in methanol at $86^{\circ} \mathrm{C}$, $2 \mathrm{~h}$ ), carboxyl reduction $\left(\mathrm{NaB}^{2} \mathrm{H}_{4}\right.$ in $\mathrm{H}_{2} \mathrm{O}$ at room temperature overnight), hydrolysis in $2 \mathrm{M}$ trifluoroacetic acid at $120^{\circ} \mathrm{C}$ for $1 \mathrm{~h}$ and $\mathrm{O}$-acetylation. Uronic acid was quantified by the carbazole/sulfuric acid method (Bitter \& Müir, 1962). The absolute configuration of monosaccharides was determined by GC and GC/MS as their acetylated (S)-(+)- or (R)-(-)-2butylglycosides as described by Gerwig et al. (1978). The GC retention times were compared with those of authentic standards. SDS-PAGE was performed as described by Tsai \& Frasch (1982).

GC and GC/MS. GC was carried out on a model 14A gas chromatograph (Shimadzu) equipped with a fused silica capillary column that had been coated with HR52 (Shinwa Chemical Industries Ltd.) or DB210 (J\&W Scientific). The temperature was programmed to remain at $180{ }^{\circ} \mathrm{C}$ for $3 \mathrm{~min}$ and then to increase to $240^{\circ} \mathrm{C}$ at $4^{\circ} \mathrm{C} \mathrm{min}^{-1}$ for the analysis of neutral and amino sugars (DB210 column), and to remain at $150{ }^{\circ} \mathrm{C}$ for $3 \mathrm{~min}$ and then to increase to $320^{\circ} \mathrm{C}$ at $5^{\circ} \mathrm{C} \mathrm{min}-1$ for permethylated and partially methylated sugars (HR52 column). GC/MS was carried out on a model DX-300 system (JEOL) with an HR52 column. Electron impact mass spectra were recorded at $70 \mathrm{eV}$ and isobutane was used as the reactant gas in chemical ionization MS.

Antisera and serological methods. Antisera against $V$. cholerae $\mathrm{O} 139$ and $\mathrm{O} 22$ were prepared by immunizing rabbits with heatkilled whole cells and antisera were absorbed with $V$. cholerae CA385 ( $\mathrm{R}$ mutant of $V$. cholerae $\mathrm{O} 1$ as an $\mathrm{R}$ antigen) as reported previously (Shimada \& Sakazaki, 1988). Passive haemolysis $(\mathrm{PH})$ and passive haemolysis inhibition (PHI) tests were performed by the method of Hisatsune et al. (1978) using sheep red blood cells (SRBC) that had been sensitized with LPS. Anti$\mathrm{O} 139$ antiserum absorbed with $\mathrm{O} 22$ cells and anti-O22 antiserum absorbed with $\mathrm{O} 139$ cells were used in absorption experiments. The absorbed antisera were obtained by the method of Sakazaki \& Donovan (1984).

\section{RESULTS AND DISCUSSION}

\section{Chemical properties of LPS}

Sugar composition of LPS. Table 1 shows the sugar composition of LPS from $V$. cholerae $\mathrm{O} 22$ and its polysaccharide moieties that were fractionated by gel filtration chromatography on Sephadex G-50. For comparative purposes, as well as for convenience, the sugar composition of O139 LPS, published previously (Hisatsune et al., 1993), is included in Table 1. The sugar composition of O22 LPS was quite similar to that of O139 LPS. Each LPS contained D-glucose, L-glycero-D-mannoheptose, colitose, D-fructose, D-glucosamine, Dquinovosamine and D-galacturonic acid. D-Galacturonic acid has not been formerly reported (Hisatsune et al., 1993) as a constituent of O139 LPS. However, in this study, a uronic acid detected in O139 and O22 LPS was identified as D-galacturonic acid. Kdo was not detectable by the conventional periodate/thiobarbituric acid test under mild conditions for acid hydrolysis. Instead, Kdo phosphate was detected in methanolysates of O22 LPS, 
Table 1. Sugar composition of $V$. cholerae 022 LPS and its polysaccharide portions after fractionation by gel filtration chromatography on Sephadex G-50

\begin{tabular}{|c|c|c|c|c|c|}
\hline \multirow[t]{2}{*}{ Sugar } & \multicolumn{5}{|c|}{ Composition [ $\left.\mu \mathrm{mol}(\mathrm{mg} \text { sample dry } w t)^{-1}\right]^{*}$} \\
\hline & 0139† & $\mathbf{O} 22$ & Frc I & Frc II & Frc III \\
\hline D-Glucose & $0 \cdot 35$ & $0 \cdot 40$ & $0 \cdot 86$ & 0.93 & - \\
\hline D-Fructose & $0 \cdot 21$ & $0 \cdot 16$ & - & - & 0.99 \\
\hline Colitose & $0 \cdot 26$ & $0 \cdot 28$ & - & - & $1 \cdot 51$ \\
\hline L-glycero-D-manno-Heptose & $0 \cdot 51$ & 0.29 & $0 \cdot 89$ & $1 \cdot 02$ & - \\
\hline D-Glucosamine & $0 \cdot 45$ & 0.42 & $0 \cdot 31$ & $0 \cdot 25$ & - \\
\hline D-Quinovosamine & $0 \cdot 12$ & $0 \cdot 11$ & $0 \cdot 27$ & $0 \cdot 14$ & - \\
\hline D-Galacturonic acid & $0 \cdot 17$ & $0 \cdot 36$ & $1 \cdot 32$ & 0.94 & $0 \cdot 16$ \\
\hline Kdo & ND & ND & ND & ND & ND \\
\hline Kdo-phosphate & + & + & NT & NT & NT \\
\hline
\end{tabular}

${ }^{*} \mathrm{ND}$, not detectable by the conventional periodate/thiobarbituric acid test; NT, not tested; -, less than $0 \cdot 01 \mu \mathrm{mol}(\mathrm{mg} \text { sample dry } \mathrm{wt})^{-1}$.

† Data for O139 LPS are taken from a previous report (Hisatsune et al., 1993).

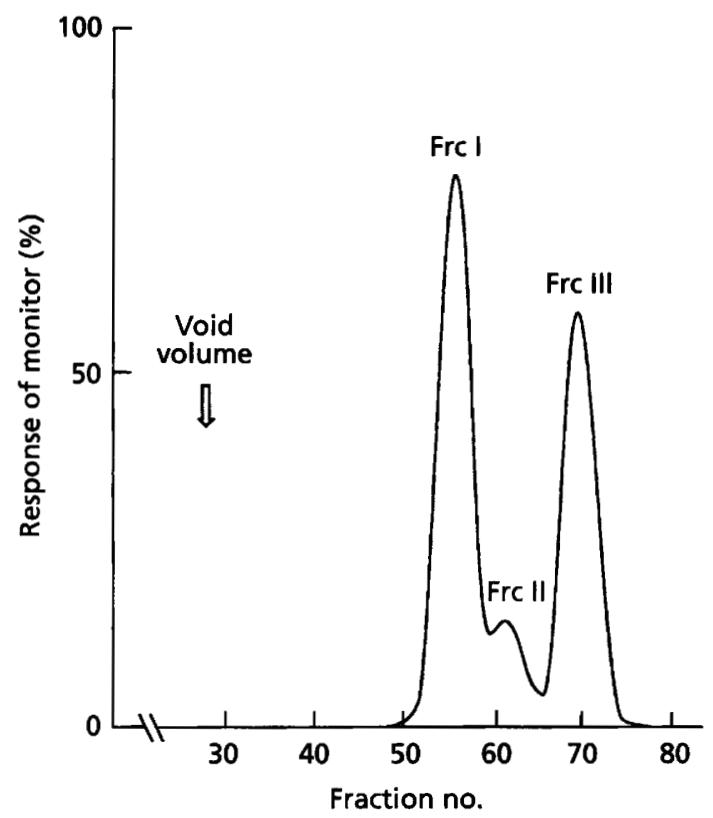

Fig. 1. Elution of the degraded polysaccharide fraction isolated from $V$. cholerae 022 LPS from a column of Sephadex G-50.

suggesting that the structure of the Kdo region of $\mathrm{O} 22$ LPS was the same as that reported for $\mathrm{O} 139$ and hence for LPS of O1 $V$. cholerae (Kondo et al., 1991a, 1992).

Polysaccharide portion of LPS. Gel filtration chromatography on Sephadex G-50 of the DPS fraction isolated from O22 LPS gave three fractions, as shown in Fig. 1, and the elution profile was almost identical to that obtained for the DPS fraction isolated from O139 LPS (Hisatsune et al., 1993). As seen in the case of O139 LPS, a polysaccharide of high molecular mass corresponding to the O-specific polysaccharide attached to the core stubs that is, in the case of a typical smooth form (S-form) LPS, eluted just after the void volume of the column, was not obtained from O22 LPS. The first (Frc I) and the second (Frc II) fractions that eluted close to each other corresponded to the core oligosaccharides and the third one (Frc III) corresponded to the monosaccharide fraction.

The sugar compositions of Frc I, II and III (Table 1) were also quite similar to those of the respective fractions obtained from O139 LPS (Hisatsune et al., 1993). Frc I contained all of the constituent sugars of LPS with the exception of colitose and D-fructose; the latter two sugars were released by the mild acid hydrolysis used for preparation of the DPS fraction and were detected in Frc III in their free forms. Frc II also lacked colitose and Dfructose. The levels of D-quinovosamine, D-glucosamine and D-galacturonic acid in Frc II were considerably lower than those estimated for Frc I, indicating that Frc II might be an incomplete core polysaccharide portion of LPS. Frc III contained mainly colitose, $\mathbf{D}$-fructose and a small amount of D-galacturonic acid in its free form.

Structural analysis. Methylation analysis, performed with mild hydrolysis conditions $\left(0.01 \mathrm{M} \mathrm{HCl}, 100^{\circ} \mathrm{C}, 30 \mathrm{~min}\right)$, revealed the presence of 1,5-di-O-acetyl-2,4-di-O-methyl3,6-dideoxygalactitol and indicated that colitose was present at a non-reducing terminus in O22 LPS. GC/MS of the product obtained after methanolysis $(1 \mathrm{M} \mathrm{HCl}$ in methanol, $86^{\circ} \mathrm{C}, 2 \mathrm{~h}$ ) and permethylation of O22 LPS and Frc I revealed a disaccharide that consisted of $\mathrm{D}$ galacturonic acid and $N$-acetyl-D-quinovosamine. After partial purification on a Sep-Pak cartridge and carboxyl reduction with $\mathrm{NaBH}_{4}$, the disaccharide was subjected to methylation analysis. GC/MS of the product revealed the presence of 1,5,6-tri- $O$-acetyl-2,3,4-tri- $O$-methylgalactitol and 1,3,5-tri-O-acetyl-2-methylacetamido-2,6-dideoxy-4$O$-methylglucitol, indicating that the disaccharide was D-galacturonic acid-(1 $\rightarrow 3)$ - $N$-acetyl-D-quinovosamine. The same disaccharide was also detected in O139 LPS. Thus, the chemical structure of the polysaccharide portions of O22 and O139 LPS were closely related. 


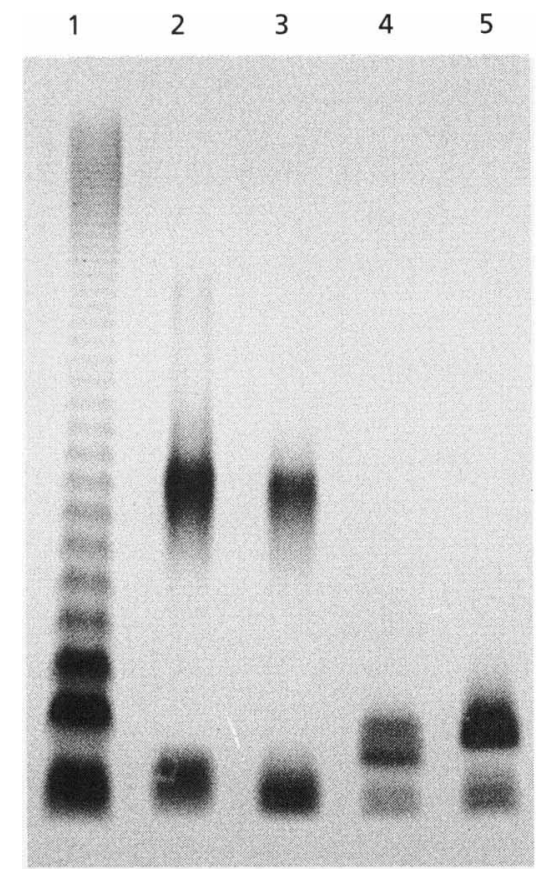

Fig. 2. Silver-stained gel after SDS-PAGE of LPS isolated from: 1 , S. typhimurium LT2; 2, V. cholerae NIH 41 (Ogawa); 3, V. cholerae 569B (Inaba); 4, V. cholerae O22; 5, V. cholerae 0139.

SDSPAGE analysis. The molecular architecture of O22 LPS was compared with that of O139 LPS by SDS-PAGE (Fig. 2). Only two bands, moving rapidly in the lowmolecular-mass region toward the bottom of the gels, were produced with the LPS. No bands such as the doublet ladders obtained typically with high-molecularmass $O$ polysaccharide chains of the smooth type (S-type) LPS from enteric bacteria, for example $S$. typhimurium and Eschericbia coli, were obtained. The banding pattern was quite similar to that for O139 LPS, showing that O22 LPS was devoid of a detectable long-chain $O$ polysaccharide that consisted of repeating units. This result was entirely consistent with that obtained from the analysis of the sugar composition of the three fractions (Frc I, II and III) prepared from the DPS by chromatography on Sephadex G-50. It is tempting to think that the more slowly migrating band might represent the polysaccharide portion of the LPS material contained in Frc I while the more rapidly migrating band might represent that contained in Frc II. Thus, despite the smooth colonies and serological O specificity, O22 LPS appeared to be an 'R-type' LPS, as was O139 LPS, on the basis of the elution profiles of the DPS after gel filtration on Sephadex G-50, the banding patterns on SDS-PAGE and the sugar composition. Recently, the term lipo-oligosaccharide (LOS) was proposed to describe the LPS of Gram-negative organisms that are devoid of the genetic ability to produce the $\mathrm{O}$ polysaccharide chain that consists of polymeric repeating units that is generally found in the Gram-negative S-type enteric bacteria (Wilkinson, 1977). O22 and O139 LPS are, in terms of molecular architecture, similar to the socalled LOS of non-enteric mucosal pathogens such as Neisseria gonorrhoeae and Haemophilus influenzae. However, as designations for these O22 and O139 LPS, 'R-type' LPS is considered to be preferable to the term LOS as argued by Hitchcock et al. (1986).

\section{Serological relationship between 0139 and 022 LPS}

Cross-reactivity of 0139 and 022 LPS. Table 2 shows the serological reactivity of O139 and O22 LPS with anti$\mathrm{O} 139$ and anti-O22 antisera, unabsorbed and absorbed with the heterologous O22 and O139 antigens. In the homologous $\mathrm{PH}$ system, unabsorbed anti-O139 antiserum had a very high haemolytic titre against SRBC that had been sensitized with homologous O139 LPS. It is noted that the unabsorbed anti-O139 antiserum also had a high titre against SRBC that had been sensitized with heterologous O22 LPS. This high activity of anti-O139 antiserum against O22 LPS on SRBC was completely eliminated after the absorption with the $\mathrm{O} 22$ antigen. The haemolytic activity of anti-O22 antiserum was also tested, before and after absorption with $\mathrm{O} 139$ antigen, against

Table 2. Passive haemolysis titres of antisera against $V$. cholerae 0139 and 022 with SRBC that had been sensitized with their LPS

\begin{tabular}{|lccccc|}
\hline LPS & \multicolumn{3}{c|}{ Haemolysis titre* } \\
\cline { 2 - 3 } & \multicolumn{2}{c}{ Anti-O139 } & & \multicolumn{2}{c|}{ Anti-O22 } \\
\cline { 2 - 3 } \cline { 5 - 6 } & No abs. $t$ & Abs. O22 $\ddagger$ & & No abs. $t$ & Abs. O139 \\
\hline O139 & 66000 & 1000 & & 900 & - \\
O22 & 22000 & - & 13000 & 9700 \\
\hline
\end{tabular}

* Results are expressed as reciprocals of the serum dilution that caused $50 \%$ haemolysis.,$- 50 \%$ haemolysis was not observed at a dilution of $1: 200$ or greater.

† Antiserum against whole cells absorbed with $V$. cholerae CA385 as an R antigen.

$\ddagger$ Antiserum against whole cells absorbed with $V$. cholerae $\mathrm{CA} 385$ as an $\mathrm{R}$ antigen and with $V$. cholerae $\mathrm{O} 22$.

\Antiserum against whole cells absorbed with $V$. cholerae $\mathrm{CA} 385$ as an $\mathrm{R}$ antigen and with $V$. cholerae O139. 
SRBC that had been sensitized with either $\mathrm{O} 139$ or $\mathrm{O} 22$ LPS. Unabsorbed anti-O22 antiserum had a very high haemolytic titre against SRBC that had been sensitized with O22 LPS. Furthermore, in the heterologous $\mathrm{PH}$ system, anti-O22 antiserum (unabsorbed) also reacted with heterologous O139 LPS on SRBC, albeit not to such a great extent, but still significantly. However, the absorption of anti-O22 antiserum with the heterologous O139 antigen entirely eliminated its activity against SRBC that had been sensitized with O139 LPS. Thus, the antiO139 antiserum contained an antibody that reacted with heterologous $\mathrm{O} 22$ antigen at a high titre (22000) and this antibody was completely removed from the anti-O139 antiserum with the $\mathrm{O} 22$ antigen, while anti-O22 antiserum contained an antibody that reacted with the heterologous O139 antigen at a low titre (900) and was also completely removed from anti-O22 antiserum with the $\mathrm{O} 139$ antigen. These results lead to the conclusion that $\mathrm{O} 139$ and $\mathrm{O} 22$ strains share at least one common $\mathrm{O}$-antigenic factor.

In PHI tests, O139 LPS and O22 LPS both strongly inhibited (the $\mathrm{ID}_{50}$ of LPS ranged from 0.03 to $0.14 \mu \mathrm{g} \mathrm{m}^{-1}$ ) the heterologous haemolytic systems of both O139 LPS-sensitized SRBC/anti-O22 antiserum and O22 LPS-sensitized SRBC/anti-O139 antiserum, which are substantially equivalent to the common antigenic factor in O139 LPS-sensitized SRBC/anti-O22 antiserum, and the common antigenic factor in $\mathrm{O} 22$ LPS-sensitized SRBC/anti-O139 antiserum systems, respectively. The results show that the $\mathrm{O}$ antigen of $\mathrm{O} 139$ is closely related to that of $\mathrm{O} 22$ in an a,b-a,c type of relationship, where $a$ is a common antigenic factor, $b$ is an O139-specific factor and $\mathrm{c}$ is an O22-specific factor.

Serological reactivity of chemically modified LPS. Treatment of O139 and O22 LPS with $48 \%$ HF resulted in total elimination of colitose and D-fructose from both LPS. Furthermore, the treatment of O139 and O22 LPS with $\mathrm{NaIO}_{4}$ yielded oxidized LPS from which D-glucose, Dfructose and D-galacturonic acid were absent. However, even though their levels were considerably reduced, the other component sugars, such as L-glycero-D-mannoheptose, colitose, D-quinovosamine and D-glucosamine, remained unoxidized by $\mathrm{NaIO}_{4}$.

The serological reactivities of the chemically modified O139 and O22 LPS were examined in the PHI system with homologous anti-O139 and anti-O22 antiserum. The $\mathrm{NaIO}_{4}$-treated O139 LPS strongly inhibited the homologous O139 LPS-sensitized SRBC/anti-O139 antiserum system to the same extent as the intact O139 LPS $\left(\mathrm{ID}_{50}\right.$ $\left.0.03 \mu \mathrm{g} \mathrm{ml}^{-1}\right)$. Although the $\operatorname{ID}_{50}\left(0.65 \mu \mathrm{g} \mathrm{ml}^{-1}\right)$ of $\mathrm{NaIO}_{4}$-treated O22 LPS in the homologous O22 LPSsensitized SRBC/anti-O22 antiserum system was higher than that of the intact O22 LPS $\left(0.03 \mu \mathrm{g} \mathrm{ml}^{-1}\right)$, the serological reactivity of O22 LPS was fully retained by $\mathrm{NaIO}_{4}$-treated O22 LPS. In contrast, HF-treated O139 and O22 LPS did not inhibit the respective homologous $\mathrm{PH}$ systems. These data seem to suggest that, at least, the D-glucose, D-fructose and D-galacturonic acid residues are not immunodominant sugars while the colitose component is related, in some unknown fashion, to the immunodominant region of the LPS molecules.
This immunochemical study of LPS isolated from $V$. cholerae $\mathrm{O} 139$ and $\mathrm{O} 22$ revealed that the sugar composition and the chemical structure of O22 LPS were quite similar to those of O139 LPS. The results obtained appear to be compatible with the interpretation that the major $\mathrm{O}$ antigen of $\mathrm{O} 139$ is the common antigen factor $\mathrm{a}$, while the major $\mathrm{O}$ antigen of $\mathrm{O} 22$ is the $\mathrm{O} 22$-specific antigen factor c.

\section{REFERENCES}

Bitter, P. \& Muir, H. M. (1962). A modified uronic acid carbazole reaction. Anal Biocbem 4, 330-334.

Gerwig, G. J., Kamerling, J. P. \& Vliegenthart, J. R. G. (1978). Determination of the $\mathrm{D}$ and $\mathrm{L}$ configuration of neutral monosaccharides by high-resolution capillary G.L.C. Carbobydr Res 62, 349-357.

Hakomori, S. (1964). A rapid permethylation of glycolipid and polysaccharide catalyzed by methylsulfinyl carbanion. $J$ Biochem (Tokyo) 55, 205-208.

Hisatsune, K., Kondo, S. \& Kobayashi, K. (1978). Lipopolysaccharides of non-O1 Vibrio cholerae (II): an immunochemical study on O-antigenic structure. Jpn J Med Sci Biol 31, 181-184.

Hisatsune, K., Kondo, S., Isshiki, Y., Iguchi, T., Kawamata, Y. \& Shimada, T. (1993). O-Antigenic lipopolysaccharide of Vibrio cholerae $\mathrm{O} 139$ Bengal, a new epidemic strain for recent cholera in the Indian subcontinent. Biochem Biopbys Res Commun 196, 1309-1315.

Hitchcock, P. J., Leive, L., Măkelă, P. H., Rietschel, E. T., Strittmatter, W. \& Morrison, D. C. (1986). Lipopolysaccharide nomenclature - past, present and future. $J$ Bacteriol 166, 699-705.

Kondo, S., Haishima, Y. \& Hisatsune, K. (1991a). Chemical structure of the 2-keto-3-deoxyoctonate (KDO) region of the lipopolysaccharide isolated from O1 Vibrio cholerae NIH 41R (Ogawa). Microbiol Immunol 35, 675-680.

Kondo, S., Zähringer, U., Seydel, U., Sinnwell, V., Hisatsune, K. \& Rietschel, E. Th. (1991b). Chemical structure of the carbohydrate backbone of Vibrio parahaemolyticus $\mathrm{O} 12$ lipopolysaccharide. Eur J Biochem 200, 689-698.

Kondo, S., Haishima, Y. \& Hisatsune, K. (1992). Taxonomic implication of the apparent undetectability of 3-deoxy-D-manno-2octulosonate $(\mathrm{Kdo})$ in lipopolysaccharides of representatives of the family Vibrionaceae and the occurrence of Kdo 4-phosphate in their inner-core regions. Carbobydr Res 231, 55-64.

Luderitz, O., Westphal, O., Staub, A. M. \& Nikaido, H. (1971). Isolation and chemical and immunological characterization of bacterial lipopolysaccharides. In Microbial Toxins, Vol. IV, pp. 145-233. Edited by G. Weinbaum, S. Kadis \& S. J. Ajl. London: Academic Press.

Sakazaki, R. \& Donovan, J. (1984). Serology and epidemiology of Vibrio cholerae and Vibrio mimicus. In Methods in Microbiology, pp. 271-289. Edited by T. Bergan. London: Academic Press.

Shimada, T. \& Sakazaki, R. (1988). R antigen of Vibrio cbolerae. Jpn J Med Sci Biol 26, 155-160.

Shimada, T., Nair, G. B., Deb, B. C., Albert, M. J., Sack, R. B. \& Takeda, Y. (1993). Outbreak of Vibrio cholerae non-O1 in India and Bangladesh. Lancet 341, 1347.

Shimada, T., Arakawa, E., Itoh, K., Okitsu, T., Matsushima, A., Asai, Y., Yamai, S., Nakazato, T., Nair, G. B., Albert, M. J. \& Takeda, Y. (1994a). Expanded serotyping scheme for Vibrio cholerae. Curr Microbiol 28, 175-178.

Shimada, T., Arakawa, E., Itoh, K., Nakazato, T., Okitsu, T., Yamai, S., Kusum, M., Nair, G. B. \& Takeda, Y. (1994b). Two strains of 
Vibrio cholerae non-O1 possessing somatic (O) antigen factors in common with $V$. cholerae serogroup 0139 synonym 'Bengal'. Curr Microbiol 29, 331-333.

Tsai, C. M. \& Frasch, C. E. (1982). A sensitive silver stain for detecting lipopolysaccharides in polyacrylamide gels. Anal Biochem 119, 115-119.

Weissbach, A. \& Hunwitz, J. (1959). The formation of 2-keto-3deoxyheptonic acid in extracts of Escherichia coli B. J Biol Chem 234, 705-709.
Westphal, O., Luderitz, O. \& Bister, R. (1952). Über die Extraktion von Bakterien mit Phenol/Wasser. Z Naturforsch 7b, 148-155.

Wilkinson, S. G. (1977). Composition and structure of bacterial lipopolysaccharides. In Surface Carbobydrates of the Procaryotic Cells, pp. 97-175. Edited by I. W. Sutherland. London: Academic Press.

Received 1 December 1995; revised 19 January 1996; accepted 23 January 1996. 